OPEN ACCESS

Edited by:

Umberto Volpe,

Marche Polytechnic University, Italy

Reviewed by:

David Ayuku,

Moi University, Kenya

Rahul Shidhaye,

Pravara Institute of Medical

Sciences, India

${ }^{*}$ Correspondence:

Modhurima Moitra

moitra@uw.edu

Specialty section: This article was submitted to Public Mental Health, a section of the journal

Frontiers in Psychiatry

Received: 03 September 2020 Accepted: 04 January 2021 Published: 27 January 2021

Citation:

Moitra M, Rahman M, Collins PY, Gohar F, Weaver M, Kinuthia J,

Rössler W, Petersen S, Unutzer J,

Saxena S, Huang KY, Lai J and

Kumar M (2021) Mental Health

Consequences for Healthcare

Workers During the COVID-19

Pandemic: A Scoping Review to Draw

Lessons for LMICs.

Front. Psychiatry 12:602614.

doi: 10.3389/fpsyt.2021.602614

\section{Mental Health Consequences for Healthcare Workers During the COVID-19 Pandemic: A Scoping Review to Draw Lessons for LMICs}

\author{
Modhurima Moitra ${ }^{1,2 *}$, Muhammad Rahman ${ }^{1}$, Pamela Y. Collins ${ }^{1,3}$, Fatima Gohar ${ }^{4}$, \\ Marcia Weaver ${ }^{1,2}$, John Kinuthia ${ }^{1,5}$, Wulf Rössler ${ }^{6}$, Stefan Petersen ${ }^{7}$, Jurgen Unutzer ${ }^{1,3}$, \\ Shekhar Saxena ${ }^{8}$, Keng Yen Huang ${ }^{9}$, Joanna Lai ${ }^{4}$ and Manasi Kumar ${ }^{1,10,11}$
}

${ }^{1}$ Department of Global Health, University of Washington, Seattle, WA, United States, ${ }^{2}$ Department of Health Metrics Sciences, University of Washington, Seattle, WA, United States, ${ }^{3}$ Department of Psychiatry and Behavioral Sciences, University of Washington, Seattle, WA, United States, ${ }^{4}$ United Nations International Children's Emergency Fund (UNICEF), New York City, NY, United States, ${ }^{5}$ Kenyatta National Hospital, Nairobi, Kenya, ${ }^{6}$ Department of Psychiatry, Psychotherapy and Psychosomatics, University Hospital of Psychiatry, University of Zurich, Zurich, Switzerland, ${ }^{7}$ Department of Women's and Children's Health, Uppsala University, Uppsala, Sweden, ${ }^{8}$ Department of Global Health and Population, Harvard TH Chan School of Public Health, Harvard University, MA, United States, ${ }^{9}$ Department of Population Health \& Child and Adolescent Psychiatry, New York University, New York City, NY, United States, ${ }^{10}$ Department of Psychiatry, University of Nairobi, Nairobi, Kenya, " ${ }^{11}$ Department of Clinical, Educational and Health Psychology, University College London, London, United Kingdom

Background: The COVID-19 pandemic has had a significant impact on the mental health of healthcare workers (HCWs) particularly in low and middle-income countries (LMICs). This scoping review provides a summary of current evidence on the mental health consequences of COVID on HCWs.

Methods: A scoping review was conducted searching PubMed and Embase for articles relevant to mental health conditions among HCWs during COVID-19. Relevant articles were screened and extracted to summarize key outcomes and findings.

Results: A total of fifty-one studies were included in this review. Depressive symptoms, anxiety symptoms, psychological trauma, insomnia and sleep quality, workplace burnout and fatigue, and distress were the main outcomes reviewed. Most studies found a high number of symptoms endorsed for depression, anxiety, and other conditions. We found differences in symptoms by sex, age, and HCW role, with female, younger-aged, frontline workers, and non-physician workers being affected more than other subgroups.

Conclusion: This review highlights the existing burden of mental health conditions reported by HCWs during COVID-19. It also demonstrates emerging disparities among affected HCW subgroups. This scoping review emphasizes the importance of generating high quality evidence and developing informed interventions for HCW mental health with a focus on LMICs.

Keywords: COVID-19, healthcare worker, mental health conditions, global health, depressive symptoms, anxiety symptoms, distress 


\section{INTRODUCTION}

From January to August 2020, over 800,000 people have died due to the COVID-19 pandemic, and health departments confirmed more than 24 million cases worldwide (1). The high transmission rate of SARS-CoV-2 and the severity of illness associated with COVID-19 have severely strained healthcare systems globally. The media and researchers continue to monitor and report the availability of hospital space, equipment, and treatment supplies (2). Shortages of personal protective equipment (PPE) and ventilators have been widely discussed in the literature $(3,4)$. The World Health Organization (WHO) has also issued guidance around managing such shortages by recommending reasonable and appropriate usage of PPE (5).

An equally important issue is the severe threat to the wellbeing of healthcare workers (HCWs) during this pandemic. HCWs currently comprise the most critical sector of the workforce at the frontlines of testing and treatment for COVID19 as well as covering other essential health services. They are at an unusually high risk of exposure to infection, and they are also at high risk of developing mental and behavioral disorders due to the high psychological toll of their intensive work in managing this highly infectious virus and grieving deaths of their colleagues $(6,7)$. Several studies and reviews have examined the psychological effects of the COVID-19 pandemic on HCWs $(8,9)$. HCWs experience symptoms of depression and anxiety, sleep problems, burnout, and general psychological distress (1012). Understandably, at this stage in the pandemic existing studies show considerable variation in sampling methods and measurement of mental health outcomes. Nevertheless, emerging differences in mental disorder prevalence by sex and worker type may be of public health significance and warrant closer review (12).

Although HCWS across the world are currently overwhelmed by the demands of care for COVID-19 patients, the impact of the pandemic on the mental health of HCWs holds significance for low and middle-income countries (LMICS) in particular. Health systems in LMICs typically do not effectively incorporate continued care modalities for chronic conditions in comparison to high-income countries (HICs). Mental healthcare services for HCWs in particular are also far less accessible in LMICs than in HICs. The onset of COVID-19 has now resulted in a tremendous increase in demand for care in health systems that are already taxed with a higher burden of acute care compared to HICs. Adequate equipment and infrastructure to treat those with complex and intensive care needs are limited in supply. Therefore, LMICs have to navigate a complex tradeoff-preventing transmission, managing existing cases, as well as keeping their health systems and economies on track. Given these challenges LMICs face, supporting the well-being of HCWs is essential to maximizing benefits to those who need their services in both the short and long term.

Given the rapidly evolving nature of the evidence, we provide an update of the current evidence base on HCW mental health in LMICs. We review evidence from all locations but use our findings to guide recommendations for LMICs. This scoping review aims to (a) summarize emerging themes and results from key quantitative and qualitative evidence published between December 2019 and June 2020 on the psychological consequences of COVID-19 on HCWs, and (b) use the updated evidence base to provide a set of broad recommendations for mental health support for HCWs in LMICs. Findings highlighted here may guide the implementation of workplace interventions in low-resourced healthcare settings and help policymakers and health ministries develop mitigation policies and programs supporting the mental health of HCWs.

\section{METHODS \\ HCW Case Definition}

For the purpose of this scoping review, we adhered to the Centers for Disease Control and Prevention (CDC) definition of HCWs which includes physicians, nurses, emergency medical personnel, dental professionals and students, medical and nursing students, laboratory technicians, pharmacists, hospital volunteers, and administrative staff (13).

\section{Search Strategy}

A scoping review was conducted using PubMed and Embase (Dec 2019-June 2020) to broadly search for studies relevant to mental health in the context of COVID-19. Details of the search strings are in the Appendix. Papers on mental health conditions among HCWs were then screened and selected for this review. According to out inclusion criteria, papers were included if they reported any quantitative or qualitative data on mental disorders or symptoms and other related conditions among healthcare workers such as psychological trauma, distress, and workplace burnout. According to our exclusion criteria, papers were excluded if they did not provide pertinent information on mental health outcomes among HCWs or were not relevant to mental health during COVID-19. Selected studies were screened and information on study characteristics and outcomes reported were extracted. Findings from our review were then summarized by study methodology, outcomes, and HCW group in the results section below. MM, MR, and MK screened studies. MM and MR extracted data from selected studies. Any questions around study eligibility were jointly discussed and resolved by MM, MR, and MK. MM summarized findings from the final list of studies. The PRISMA study selection flowchart is provided in Figure 1.

\section{RESULTS}

A total of 51 studies were selected for this review. Table 1 shows the countries represented in these studies. A majority, $61 \%$ of selected studies, originated from China. Based on World Bank Income level classifications, $72.5 \%$ of the studies were from Low and Middle Income Countries (LMICs). The sample size of included studies ranged from 52 to 14825 with a median sample size of 548. Of the 39 studies that reported data on the distribution of HCWs by sex, the median proportion of female HCWs was 64\%. However, more than half the sample comprised female HCWs in $79 \%$ of these studies. All HCWs (physicians, nurses, and other workers) were represented in $78 \%$ of studies. Approximately $6 \%$ of studies reported exclusively 


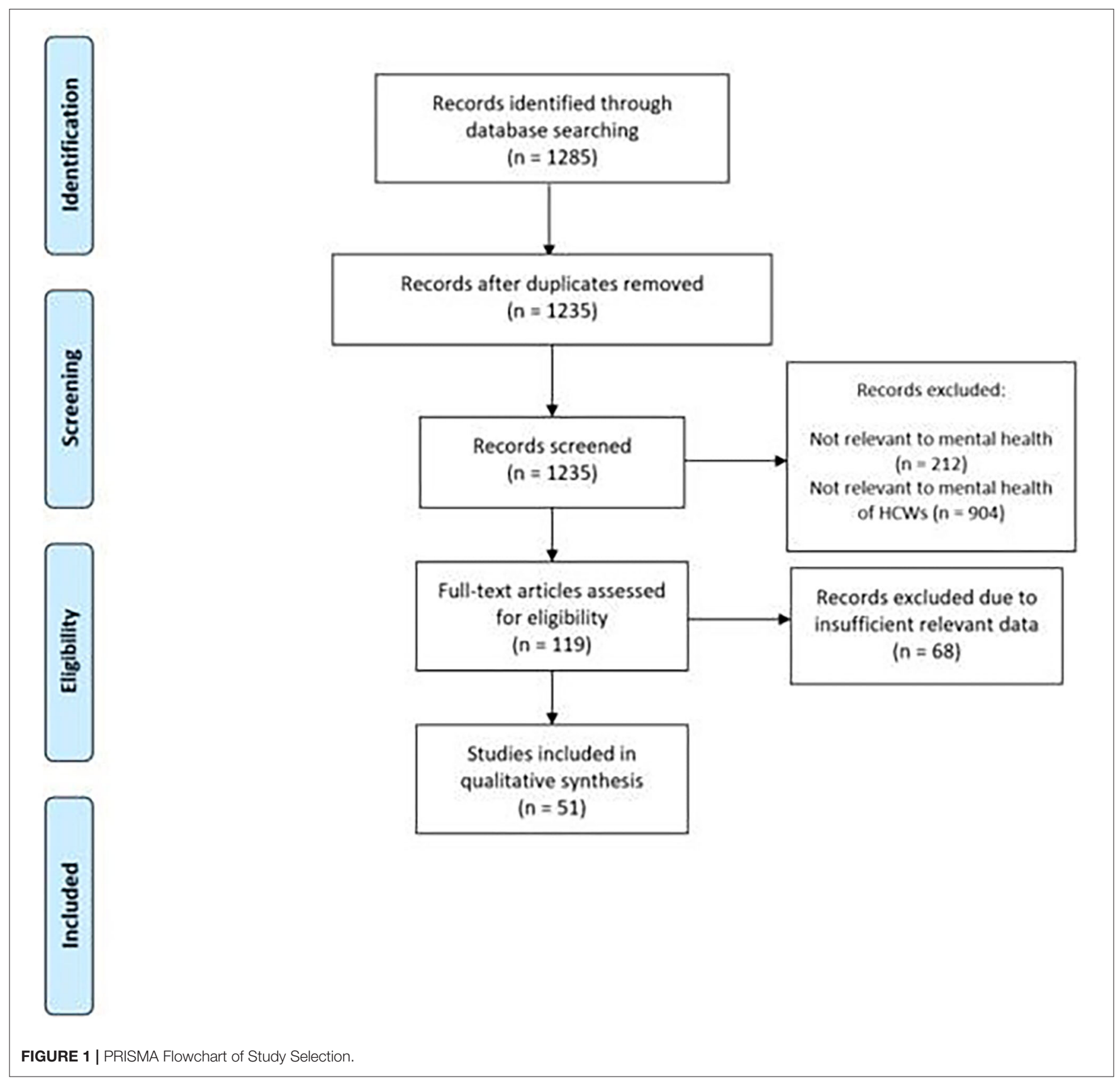

on non-physician samples (example nurses, therapists) and $16 \%$ reported exclusively on physicians. Frontline or first-line medical workers (FMW), who typically are first responders to COVID-19 crises, are mentioned in the sample descriptions of nine studies.

The studies predominantly made use of a cross-sectional study design ( $88 \%$ of studies). Nearly all studies used a convenience sampling strategy and online data collection methods. Symptoms of anxiety ( $65 \%$ of studies), depression ( $57 \%$ of studies), and distress (37\% of studies) were the most commonly studied conditions. The Patient Health Questionnaire (PHQ) (33\% of studies) and the Generalized Anxiety Disorder Scale (GAD) (29\% of studies) were the most commonly used instruments to measure symptoms of depression and anxiety, respectively.

\section{Anxiety Symptoms}

HCWs frequently reported symptoms of anxiety (14, 39, 47, 50, 57, 60). Anxiety was frequently associated with lowered sleep quality and insomnia and was common among those living with infants or elderly family members $(32,47,58,61)$. Severe anxiety was associated with being in direct treatment contact with COVID-19 and the lack of adequate personal protective equipment (PPE) $(32,36)$. Differences by age were also reported, with younger HCWs experiencing higher levels of 
TABLE 1 | List of Selected Studies and Study Characteristics.

\begin{tabular}{|c|c|c|c|c|}
\hline References & Country & $\begin{array}{l}\text { World bank income } \\
\text { level }\end{array}$ & $\begin{array}{l}\text { Healthcare worker sample } \\
\text { description }\end{array}$ & $\begin{array}{l}\text { Mental health } \\
\text { conditions/stressors included }\end{array}$ \\
\hline Alhaj et al. (14) & $\begin{array}{l}\text { Multi-country: Canada, } \\
\text { the United States, Kuwait, } \\
\text { Saudi Arabia, Serbia, and } \\
\text { Italy }\end{array}$ & $\begin{array}{l}\text { High income and upper } \\
\text { middle income }\end{array}$ & Neurosurgery residents & $\begin{array}{l}\text { Mental health, workplace stress } \\
\text { (lack of social life) }\end{array}$ \\
\hline Amerio et al. (15) & Italy & High income & General practitioners & $\begin{array}{l}\text { Depressive symptoms, anxiety } \\
\text { symptoms, insomnia, distress }\end{array}$ \\
\hline Chen et al. (17) & China & Upper middle income & Doctors and nurses & $\begin{array}{l}\text { Depressive symptoms, anxiety } \\
\text { symptoms, distress, insomnia }\end{array}$ \\
\hline Chen et al. (18) & China & Upper middle income & Medical workers & Mental health \\
\hline Chen et al. (19) & Taiwan & High income & $\begin{array}{l}\text { Healthcare workers in a tertiary } \\
\text { referral center }\end{array}$ & Mental health \\
\hline $\begin{array}{l}\text { Chung and } \\
\text { Yeung (21) }\end{array}$ & China & Upper middle income & All healthcare workers & Depressive symptoms \\
\hline $\begin{array}{l}\text { Civantos et al. } \\
\text { (22) }\end{array}$ & United States & High income & $\begin{array}{l}\text { Otaloaryngology physicians and } \\
\text { residents }\end{array}$ & $\begin{array}{l}\text { Depressive symptoms, anxiety } \\
\text { symptoms, distress, workplace } \\
\text { burnout }\end{array}$ \\
\hline $\begin{array}{l}\text { Dimitriu et al. } \\
\text { (23) }\end{array}$ & Romania & High income & $\begin{array}{l}\text { First-Line medical residents in } \\
\text { emergency unit, ICU, radiology, } \\
\text { general surgery, gynecology, and } \\
\text { orthopedics }\end{array}$ & Workplace burnout \\
\hline Du et al. (24) & China & Upper middle income & Frontline workers & $\begin{array}{l}\text { Depressive symptoms, anxiety } \\
\text { symptoms, distress, sleep quality }\end{array}$ \\
\hline $\begin{array}{l}\text { Huang and Zhao } \\
\text { (29) }\end{array}$ & China & Upper middle income & $\begin{array}{l}\text { Doctors, nurses, and health } \\
\text { administrators }\end{array}$ & $\begin{array}{l}\text { Depressive symptoms, anxiety } \\
\text { symptoms, and sleep quality }\end{array}$ \\
\hline Huang et al. (30) & China & Upper middle income & First-Line medical staff & $\begin{array}{l}\text { Anxiety symptoms, } \\
\text { psychological trauma symptoms }\end{array}$ \\
\hline $\begin{array}{l}\text { Khanna et al. } \\
\text { (31) }\end{array}$ & India & Lower middle income & $\begin{array}{l}\text { Ophthamologists and } \\
\text { ophthamology trainees }\end{array}$ & Depressive symptoms \\
\hline Khusid et al. (32) & United States & High income & Urology residents & $\begin{array}{l}\text { Anxiety symptoms, depressive } \\
\text { symptoms }\end{array}$ \\
\hline Lai et al. (33) & China & Upper middle income & $\begin{array}{l}\text { Healthcare workers in fever } \\
\text { clinics or COVID wards }\end{array}$ & $\begin{array}{l}\text { Anxiety symptoms, depressive } \\
\text { symptoms, distress, insomnia }\end{array}$ \\
\hline Li et al. (34) & China & Upper middle income & First-Year training physicians & $\begin{array}{l}\text { Anxiety symptoms, depressive } \\
\text { symptoms, mood valence, } \\
\text { workplace violence }\end{array}$ \\
\hline Liang et al. (35) & China & Upper middle income & Doctors and nurses & $\begin{array}{l}\text { Depressive symptoms, anxiety } \\
\text { symptoms }\end{array}$ \\
\hline Liu et al. (36) & China & Upper middle income & Medical staff & Anxiety symptoms \\
\hline
\end{tabular}


TABLE 1 | Continued

\begin{tabular}{|c|c|c|c|c|}
\hline References & Country & $\begin{array}{l}\text { World bank income } \\
\text { level }\end{array}$ & $\begin{array}{l}\text { Healthcare worker sample } \\
\text { description }\end{array}$ & $\begin{array}{l}\text { Mental health } \\
\text { conditions/stressors included }\end{array}$ \\
\hline Lu et al. (37) & China & Upper middle income & $\begin{array}{l}\text { Doctors, nurses, and } \\
\text { administrative staff }\end{array}$ & $\begin{array}{l}\text { Anxiety symptoms, depressive } \\
\text { symptoms }\end{array}$ \\
\hline $\begin{array}{l}\text { Morgantini et al. } \\
\text { (38) }\end{array}$ & $\begin{array}{l}60 \text { countries including } \\
\text { Brazil, Sweden, Italy, and } \\
\text { USA }\end{array}$ & $\begin{array}{l}\text { Various including high and } \\
\text { upper middle income }\end{array}$ & Healthcare professionals & Workplace burnout \\
\hline Poddar et al. (40) & India & Lower middle income & $\begin{array}{l}\text { Dermatologists and } \\
\text { non-dermatologists (internists, } \\
\text { pediatricians, } \\
\text { otorhinolaryngologists, } \\
\text { respiratory medicine specialists, } \\
\text { psychiatrists, and general } \\
\text { physicians) }\end{array}$ & Perceived stress \\
\hline Liu et al. (42) & China & Upper middle income & Physicians and nurses & Anxiety symptoms, burnout \\
\hline $\begin{array}{l}\text { Ramaci et al. } \\
(43)\end{array}$ & Italy & High income & Doctors and nurses & $\begin{array}{l}\text { Workplace burnout and fatigue, } \\
\text { self-worth, fear }\end{array}$ \\
\hline Rossi et al. (44) & Italy & High income & Healthcare workers & $\begin{array}{l}\text { Anxiety symptoms, depressive } \\
\text { symptoms, distress, insomnia, } \\
\text { psychological trauma }\end{array}$ \\
\hline $\begin{array}{l}\text { Salman et al. } \\
\text { (45) }\end{array}$ & Pakistan & Lower middle income & $\begin{array}{l}\text { Medical doctors, nurses, } \\
\text { pharmacists }\end{array}$ & $\begin{array}{l}\text { Anxiety symptoms, depressive } \\
\text { symptoms, coping strategies }\end{array}$ \\
\hline Shariati et al. (46) & Iran & Upper middle income & Psychiatric trainees & Distress \\
\hline Sheng et al. (47) & China & Upper middle income & Nursing interns & $\begin{array}{l}\text { Anxiety symptoms, depressive } \\
\text { symptoms, sleep quality }\end{array}$ \\
\hline Tian et al. (51) & China & Upper middle income & Frontline health professionals & $\begin{array}{l}\text { Anxiety symptoms, depressive } \\
\text { symptoms, distress, insomnia } \\
\text { severity }\end{array}$ \\
\hline Wang et al. (52) & China & Upper middle income & Pediatric healthcare workers & $\begin{array}{l}\text { Anxiety symptoms, depressive } \\
\text { symptoms, sleep quality }\end{array}$ \\
\hline Zhang et al. (53) & China & Upper middle income & $\begin{array}{l}\text { Medical and non-medical } \\
\text { healthcare workers }\end{array}$ & $\begin{array}{l}\text { Anxiety symptoms, depressive } \\
\text { symptoms, insomnia }\end{array}$ \\
\hline Wu et al. (54) & China & Upper middle income & $\begin{array}{l}\text { Medical staff and college } \\
\text { students }\end{array}$ & Distress \\
\hline Wu and Wei (55) & China & Upper middle income & Frontline medical staff & $\begin{array}{l}\text { Anxiety symptoms, depressive } \\
\text { symptoms, insomnia, mental } \\
\text { health status }\end{array}$ \\
\hline Xing et al. (56) & China & Upper middle income & Medical personnel & Medical personnel \\
\hline Xu et al. (57) & China & Upper middle income & Surgical medical staff & $\begin{array}{l}\text { Anxiety symptoms, depressive } \\
\text { symptoms }\end{array}$ \\
\hline Yang et al. (58) & South Korea & High income & Physical therapists & $\begin{array}{l}\text { Anxiety symptoms, depressive } \\
\text { symptoms }\end{array}$ \\
\hline Yin et al. (59) & China & Upper middle income & Frontline healthcare workers & $\begin{array}{l}\text { Sleep quality, psychological } \\
\text { trauma symptoms }\end{array}$ \\
\hline
\end{tabular}


TABLE 1 | Continued

\begin{tabular}{|c|c|c|c|c|}
\hline References & Country & $\begin{array}{l}\text { World bank income } \\
\text { level }\end{array}$ & $\begin{array}{l}\text { Healthcare worker sample } \\
\text { description }\end{array}$ & $\begin{array}{l}\text { Mental health } \\
\text { conditions/stressors included }\end{array}$ \\
\hline Zhang et al. (60) & Iran & Upper middle income & $\begin{array}{l}\text { Depressive symptoms, distress, } \\
\text { anxiety symptoms, job } \\
\text { satisfaction }\end{array}$ & $\begin{array}{l}\text { Doctors, nurses, radiologists, } \\
\text { technicians }\end{array}$ \\
\hline Zhang et al. (61) & China & Upper middle income & Hospital staff & $\begin{array}{l}\text { Anxiety symptoms, depressive } \\
\text { symptoms, insomnia }\end{array}$ \\
\hline Liu et al. (62) & China & Upper middle income & Doctors and nurses & $\begin{array}{l}\text { Anxiety symptoms, depressive } \\
\text { symptoms, distress }\end{array}$ \\
\hline Zhou et al. (63) & China & Upper middle income & Frontline medical workers & $\begin{array}{l}\text { Distress, mental health status, } \\
\text { sleep quality }\end{array}$ \\
\hline Zhu et al. (64) & China & Upper middle income & $\begin{array}{l}\text { Doctors, nurses, and medical } \\
\text { technicians }\end{array}$ & $\begin{array}{l}\text { Anxiety symptoms. Depressive } \\
\text { symptoms, distress }\end{array}$ \\
\hline
\end{tabular}

anxiety compared to older age groups $(30,44,45)$. Differences between male and female HCWs were also found, with women experiencing more symptoms of anxiety compared to men (20, $22,24,30,32,44,45,64)$. Studies that examined mental health outcomes before and during the COVID-19 outbreak found a significant increase in reported anxiety symptoms in the outbreak period compared to the non-outbreak period $(19,34,57)$.

Differences by HCW role: Differences in anxiety symptoms were also reported by HCW role and proximity to patients with COVID-19. In a study examining mental health conditions among physicians, nurses, and other professionals, nurses, and trainees reported higher anxiety than physicians (27). Similar findings are reported elsewhere with HCWs in non-physician roles such as nurses experiencing greater anxiety than those in physician roles $(20,29,62,64)$. Front-line medical workers who are typically required to respond to COVID-19 emergencies experience higher levels of anxiety compared to non-frontline HCWs $(28,51,55)$. HCWs in patient care roles experience higher anxiety than those in non-patient care roles or administrative roles $(37,53)$. Similarly, those working in ICU wards reported greater anxiety compared to those who worked in isolation wards or other departments (45).

\section{Depressive Symptoms}

Symptoms of depression are highly prevalent among HCWs. Similar to anxiety symptoms, depressive symptoms were also associated with poor sleep quality and insomnia (47, 52, 61). Moderate to severe depressive symptoms were also linked to higher access to COVID information, lack of adequate PPE, and treating more COVID-19 patients (15). Studies that prospectively evaluated mental health outcomes found a significant increase in symptoms of depression in the outbreak period compared to the non-outbreak period $(19,34,57)$.

Several studies showed that younger age was associated with a higher number of reported depressive symptoms (31, 35, 44, $45,48)$. Female HCWs reported experiencing a higher severity of depressive symptoms than males in several studies that examined differences by sex $(24,31-33,44,45,64)$ with the exception of one study that reported higher depressive symptom severity in male HCWs compared to female counterparts (20). A study of otolaryngology physicians found no sex differences in depressive symptoms among HCWs (22).

Reported depressive symptoms also differed by healthcare roles and level of professional experience. A prospective cohort of first-year trainee physicians in China reported significant increases in depressive symptom severity during the COVID19 outbreak (34). Nurses and other HCWs in non-physician roles experienced greater depressive symptom severity compared to HCWs in physician roles $(20,27,28,33,62,64)$. Those in government health services reported more depressive symptoms compared to other sectors such as private practice or NGOs (31). Proximity to COVID-19 crises also affect depression severity (45). A study of frontline medical workers (FMWs) in China found that over $45 \%$ of FMWs experienced symptoms of depression (51). Several studies showed that FMWs reported greater depressive symptom severity when compared to nonFMWs $(28,33,55)$. Similarly, HCWs in medical roles experience greater depression symptom severity than those in non-medical roles in healthcare (53).

\section{Insomnia and Sleep Quality}

Insomnia and poor sleep quality were commonly reported by HCWs alongside depression, anxiety and stress (15, 17, 33, 47, 59). Similar to depression and anxiety, there are differences that emerged by sex and occupational role. A study conducted among hospital staff in China between January and February 2020 showed that females reported higher rates of insomnia compared to males (61). The same study also found that nurses experienced greater insomnia severity (ascertained using the Insomnia Severity Index-which measures the severity and frequency of the sleep disorder insomnia) compared to doctors and other medical staff (61). Similar findings were also reported in a study of mental health outcomes among HCWs in Italy: nurses and healthcare assistants reported greater insomnia severity than physicians, general practitioners and other medical professions (44). Proximity to COVID-19 cases was also associated with poor sleep quality (ascertained using the Pittsburgh Sleep Quality Index-which measures recent deviances in usual sleeping habits) and insomnia. Frontline workers and medical HCWs 
TABLE 2A | Mental health of HCWS during COVID-19: recommendations for research.

\section{Recommendations for Research on COVID related \\ consequences on HCWs and mitigation strategies}

Better delineation of study samples-which worker roles are included or not and how those may impact study findings

Assess any reporting bias that may be due to data collection methods (e.g., online vs. in-person data collection)

Use of culturally informed screening instruments to assess mental health conditions

Addressing stigma-reduction on an urgent basis, intersectional nature of stigma, public health measures to educate populations about distress associated with increased stigma

Prospective assessment of samples to determine changes in duration and severity of symptoms

Continued examination of socioeconomic factors, including gender, race, and ethnic identity, that may affect mental health of HCWs

Continued examination of workplace factors that may influence the mental health of HCWs

Evaluation of intervention efficacy using appropriate measures based in evaluation science principles

Evaluation of policies and human resource management plans enacted to support HCWs and workplace mental health policy development and evaluation in LMICs and enhanced training, research and support to those working in humanitarian context

experienced worse sleep quality and higher insomnia severity than non-frontline workers and non-medical HCWs $(41,53,55)$.

\section{Other Related Conditions (Distress, Psychological Trauma, and Burnout)}

The studies in this review also reported additional outcomes such as distress, psychological trauma, and workplace burnout. High levels of workplace exhaustion and fatigue were prevalent (38, 42). Younger HCWs reported higher prevalence of symptoms of psychological trauma and distress compared to older HCWs (44, 48). Females, more than males, reported psychological trauma, burnout due to stressful work conditions, and distress (22, 29, $40,59,64)$ though one study reported greater psychological trauma symptoms among male HCWs (48). These sex differences also existed among physicians, with female physicians reporting higher burnout than their male counterparts $(22,43)$. Differences by HCW role were reported with nurses and healthcare assistants reporting greater distress than those in physician roles $(44,48)$. Nurses, trainees, and non-physicians reported also higher stress (20, 27, 59, 64). Among physician roles, resident physicians experienced greater burnout than attending physicians and physicians in branches of general surgery, gynecology, and orthopedics also reported higher burnout $(22,23)$. In terms of work duration, permanent workers reported greater burnout and fatigue compared to temporary workers (43).

\section{DISCUSSION}

Our findings highlight the high prevalence frequency of anxiety, depressive symptoms, insomnia, burnout, and distress that
TABLE 2B | Mental health of HCWs during COVID-19: recommendations for policy and practice.

\section{Recommendations for policy and practice}

Addressing emerging disparities by worker role, age, sex, socioeconomic status, race, and ethnic identity; Policies focused on equity and more egalitarian workplace culture

Developing strategies to deal with protracted stress, grief, bereavement and using team science principles to improve organizational climate and leadership skills in managers and senior staff; routine assessment of stress, burn out and other mental health indicators and provision of timely, holistic support

Decision support system to help HCW address mental health and well-being of diverse at-risk populations and those with multimorbidity; inclusion of self-care modules to attend to their own stress and strains; especially enhanced support for the well-being and work performance of HCWs in humanitarian settings and those working directly with COVID-19 response and with key populations

Human rights-based and social justice services and training of HCWs who are embedded within ongoing emergency response

Development of brief, low intensity interventions addressing resilience, emergency preparedness and improved mental health outcomes, looking at short and long term mental health outcomes

Social and family needs of HCWs to be addressed at health systems level

HCWs have experienced during the COVID-19 pandemic and are consistent with existing reviews (12, 65-70). Reviews published on this topic either cover shorter timeframes compared to this current review or report on studies only from China. Meta-analytic approaches used by some reviews may be subject to important methodological limitations. For instance, an earlier meta-analysis by Pappa et al. synthesized results from 13 studies to provide prevalence estimates of depression, anxiety, and insomnia (12). However, the paper also highlights limited data availability and important methodological sources of variation that contribute to between-study heterogeneity. Similar concerns around the lack of validated mental health outcome measures and appropriate comparisons to pre-outbreak time periods are also cited by Thombs et al. (71).

Our current review includes 51 studies with substantial variation in methodology and results reported which precluded the use of a meta-analytic approach and made a narrative review of results most suitable for this work. These studies employed a variety of instruments and used different cutoff thresholds to assess severity. Notably, the magnitude and severity of reported mental health outcomes may vary based on the validity and sensitivity of the measurement tools. The selection criteria of HCW samples also varied between studies, and HCWs' degree of exposure to patients with COVID-19 care also differed. It is likely that the degree of proximity to COVID-19 treatment may determine the extent to which HCWs experience grief, fear, anxiety, or concerns about their personal safety.

Some limitations are important to note. First, our search was conducted from December 2019 to June 2020 which covers $\sim 7$ months of the COVID-19 pandemic. Given the rapidly evolving literature in this area at present, it is possible that new studies may have been indexed later that we were unable to include in 
this review. Second, the timeline for this rapid review allowed for the search of only two electronic databases. Finally, there were very few studies from lower-middle income countries that could be used in our report indicating a need for more studies from these locations to improve the quality of available evidence.

Despite the methodological variation present in the studies reviewed, there are important themes that are predominant in the evidence thus far. Significant differential patterns by age, sex, and HCW role have emerged. Younger, female, nonphysician HCWS, and frontline workers appear to be more vulnerable to poor mental health as seen in several studies reported above. Workplace burnout is also highly prevalent among these subgroups and is important to study further as it co-occurs with other mental health conditions such as depression (72). These differences based on demographics and work role are also observed in earlier reviews (12). It is important to note that the majority of non-physician HCWs are typically female, and it will be useful to disentangle the effects of sex and HCW role in future work. In our review, only 9 studies reported inclusion of frontline workers in their samples and 3 studies sampled nonphysicians exclusively. Therefore, gaining a more comprehensive understanding of mental health in these subgroups will require additional studies. Nonetheless, such differences as seen in our review and elsewhere are likely to have varying consequences for HCWs in the larger context of workplace equity during major global health crises.

Support of HCW mental health in LMICs must be tailored from the perspective of these differences that could be potential harbingers of emerging disparities. These could likely place specific HCW subgroups (female HCWs, younger HCWs, nonphysician workers) at a disproportionately higher risk for developing mental disorders. LMICs are known to experience challenges in investment in healthcare resources including inadequate personnel. Adaptations in healthcare delivery models such as repurposing of health facilities, task shifting without competency based trainings and supportive supervision, and redeployment from different departments to accommodate high patient volumes will inevitably place a greater burden on already vulnerable $\mathrm{HCW}$ subgroups. In addition to the burden of these stressors, HCWs are also likely to face economic changes such

\section{REFERENCES}

1. Dong E, Du H, Gardner L. An interactive web-based dashboard to track COVID-19 in real time. Lancet Infect Dis. (2020) 20:533-4. doi: 10.1016/S1473-3099(20)30120-1

2. COVID I, Murray CJ. Forecasting COVID-19 impact on hospital bed-days, ICU-days, ventilator-days and deaths by US state in the next 4 months. MedRxiv. (2020).

3. Ranney ML, Griffeth V, Jha AK. Critical supply shortages-the need for ventilators and personal protective equipment during the Covid-19 pandemic. N Engl J Med. (2020) 382:e41. doi: 10.1056/NEJMp2006141

4. Lancet T. COVID-19: protecting health-care workers. Lancet. (2020) 395:922. doi: 10.1016/S0140-6736(20)30644-9

5. World Health Organization. Rational Use of Personal Protective Equipment (PPE) for Coronavirus Disease (COVID-19): Interim Guidance, 19 March 2020. Geneva: World Health Organization (2020). as exacerbated poverty and inequality that are projected to take place in LMICs due to the pandemic (73). Therefore, these have important implications for future research and intervention development. International institutes have developed guidelines to address mental health burden of HCWs. The United Nations and WHO published guidelines and recommendations on mitigating the mental health impact of COVID-19 on HCWs $(74,75)$. The National Academy of Medicine has also published strategies to support mental health of HCWs and clinicians during COVID-19 (76). In the context of the evidence presented above and by these major organizations, some general guidelines and recommendations are provided below in Tables $\mathbf{2 A}, \mathbf{B}$. These are aimed at improving both the generation of high quality evidence through research as well as intervention strategies to implement in practice for the support of HCWs' mental health in LMICs.

\section{CONCLUSION}

HCWs experience considerable adverse mental health outcomes in the context of COVID-19. Findings summarized in this review can inform approaches to monitoring and data collection for mental health outcomes among HCWs in LMICs. These findings can aid the tailoring of interventions and support strategies implemented at the institutional and national levels to mitigate and manage mental health conditions among HCWs in LMICs with a specific focus on vulnerable HCW subgroups.

\section{AUTHOR CONTRIBUTIONS}

MM, MR, and MK searched and screened studies. MM and MK extracted data from selected studies. MM wrote first draft of manuscript. All authors reviewed and edited manuscript.

\section{SUPPLEMENTARY MATERIAL}

The Supplementary Material for this article can be found online at: https://www.frontiersin.org/articles/10.3389/fpsyt. 2021.602614/full\#supplementary-material

6. Xiao J, Fang M, Chen Q, He B. SARS, MERS and COVID-19 among healthcare workers: a narrative review. J Infect Public Health. (2020). 13:8438. doi: 10.1016/j.jiph.2020.05.019

7. Danielle Renwick SD. Exclusive: Over 900 Health Workers Have Died of COVID-19. And the Toll Is Rising. Kaiser Health News. (2020). Retrieved from: https://khn.org/news/exclusive-over-900-health-workershave-died-of-covid-19-and-the-toll-is-rising/

8. Greenberg N. Mental health of health-care workers in the COVID-19 era. Nat Rev Nephrol. (2020). 16:425-6. doi: 10.1001/jamahealthforum.20 20.0397

9. Gold JA. Covid-19: adverse mental health outcomes for healthcare workers. BMJ. 369:m1815. doi: 10.1136/bmj. m1815

10. Greenberg N, Docherty M, Gnanapragasam S, Wessely S. Managing mental health challenges faced by healthcare workers during covid-19 pandemic. BMJ. (2020) 368:m1211. doi: 10.1136/bmj.m1211 
11. Park JS, Lee EH, Park NR, Choi YH. Mental health of nurses working at a government-designated hospital during a MERSCoV outbreak: a cross-sectional study. Arch Psychiatr Nurs. (2018) 32:2-6. doi: 10.1016/j.apnu.2017.09.006

12. Pappa S, Ntella V, Giannakas T, Giannakoulis VG, Papoutsi E, Katsaounou P. Prevalence of depression, anxiety, and insomnia among healthcare workers during the COVID-19 pandemic: a systematic review and meta-analysis. Brain Behav Immun. (2020). 88:901-7. doi: 10.2139/ssrn. 3594632

13. CDC. National Center for Immunization and Respiratory Diseases. CDC (2020)Available online at: https://www.cdc.gov/vaccines/adults/rec-vac/hcw. html

14. Alhaj AK, Al-Saadi T, Mohammad F, Alabri S. Neurosurgery residents perspective on the COVID-19: knowledge, readiness, and impact of this pandemic. World Neurosurg. (2020) 139:e84858. doi: 10.1016/j.wneu.2020.05.087

15. Amerio A, Bianchi D, Santi F, Costantini L, Odone A, Signorelli C, et al. Covid-19 pandemic impact on mental health: a web-based cross-sectional survey on a sample of Italian general practitioners. Acta Biomed. (2020) 91:83-8. doi: 10.23750/abm.v91i2.9619

16. Cai W, Lian B, Song X, Hou T, Deng G, Li H. A cross-sectional study on mental health among health care workers during the outbreak of corona virus disease 2019. Asian J Psychiatry. (2020) 51:102111. doi: 10.1016/j.ajp.2020.102111

17. Chen Q, Liang M, Li Y, Guo J, Fei D, Wang L, et al. Mental health care for medical staff in China during the COVID-19 outbreak. Lancet Psychiatry. (2020) 7:e15-6. doi: 10.1016/S2215-0366(20)30078-X

18. Chen Y, Jin YL, Zhu LJ, Fang ZM, Wu N, Du MX, et al. The network investigation on knowledge, attitude and practice about Novel coronavirus pneumonia of the residents in Anhui Province. Zhonghua Yu Fang Yi Xue Za Zhi. (2020) 54:E004. doi: 10.3760/cma.j.issn.0253-9624.2020.0004

19. Chen NH, Wang PC, Hsieh MJ, Huang CC, Kao KC, Chen YH, et al. Impact of severe acute respiratory syndrome care on the general health status of healthcare workers in Taiwan. Infect Control Hosp Epidemiol. (2007) 28:759. doi: $10.1086 / 508824$

20. Choudhury T, Debski M, Wiper A, Abdelrahman A, Wild S, Chalil S, et al. Covid-19 pandemic: looking after the mental health of our healthcare workers. JOccup Environ Med. (2020) 62:e373-6. doi: 10.1097/JOM.0000000000001907

21. Chung JP, Yeung WS. Staff mental health self-assessment during the COVID19 outbreak. East Asian Arch Psychiatry. (2020) 30:34. doi: 10.12809/eaap2014

22. Civantos AM, Byrnes Y, Chang C, Prasad A, Chorath K, Poonia SK, et al. Mental health among otolaryngology resident and attending physicians during the COVID-19 pandemic: national study. Head Neck. (2020) 42:15971609. doi: 10.1002/hed.26292

23. Dimitriu MC, Pantea-Stoian A, Smaranda AC, Nica AA, Carap AC, Constantin VD, et al. Burnout syndrome in romanian medical residents in time of the COVID-19 pandemic. Med Hypothes. (2020) 144:109972. doi: 10.1016/j.mehy.2020.109972

24. Du J, Dong L, Wang T, Yuan C, Fu R, Zhang L, et al. Psychological symptoms among frontline healthcare workers during COVID-19 outbreak in Wuhan. Gen Hosp Psychiatry. (2020) 67:144-5. doi: 10.1016/j.genhosppsych.2020.03.011

25. Fawaz M, Samaha A. The psychosocial effects of being quarantined following exposure to COVID-19: a qualitative study of Lebanese health care workers. Int J Sock Psychiatry. (2020) 66:560-5. doi: 10.1177/0020764020932202

26. Feng MC, Wu HC, Lin HT, Lei L, Chao CL, Lu CM, et al. Exploring the stress, psychological distress, and stress-relief strategies of Taiwan nursing staffs facing the global outbreak of COVID-19. Hu Li Za Zhi. (2020) 67:6474. doi: 10.6224/JN.202006_67(3).09

27. García-Fernández L, Romero-Ferreiro V, López-Roldán PD, Padilla S, Calero-Sierra I, Monzó-García M, et al. Mental health impact of COVID19 pandemic on Spanish healthcare workers. Psychol Med. (2020) 13. doi: $10.1017 /$ S0033291720002019

28. Guo J, Liao L, Wang B, Li X, Guo L, Tong Z, et al. Psychological effects of COVID-19 on hospital staff: a national cross-sectional survey of China mainland. Preprints Lancet. (2020). doi: 10.2139/ssrn. 3550050

29. Huang Y, Zhao N. Generalized anxiety disorder, depressive symptoms and sleep quality during COVID-19 outbreak in China: a web-based cross-sectional survey. Psychiatry Res. (2020) 288:112954. doi: 10.1016/j.psychres.2020.112954
30. Huang JZ, Han MF, Luo TD, Ren AK, Zhou XP. Mental health survey of 230 medical staff in a tertiary infectious disease hospital for COVID19. Zhonghua Lao Dong Wei Sheng Zhi Ye Bing Za Zhi. (2020) 38:1925. doi: 10.3760/cma.j.cn121094-20200219-00063

31. Khanna RC, Honavar SG, Metla AL, Bhattacharya A, Maulik PK. Psychological impact of COVID-19 on ophthalmologists-in-training and practising ophthalmologists in India. Indian J Ophthalmol. (2020) 68:9948. doi: 10.4103/ijo.IJO_1458_20

32. Khusid JA, Weinstein CS, Becerra AZ, Kashani M, Robins DJ, Fink LE et al. Well-being and education of urology residents during the COVID-19 pandemic: results of an American national survey. Int J Clin Pract. (2020). 74:1-8. doi: 10.22541/au.158981507.73370840

33. Lai J, Ma S, Wang $\mathrm{Y}$, Cai $\mathrm{Z}$, Hu J, Wei $\mathrm{N}$, et al. Factors associated with mental health outcomes among health care workers exposed to coronavirus disease (2019). JAMA Netw Open. (2020) 3:e203976. doi: 10.1001/jamanetworkopen.2020.3976

34. Li W, Frank E, Zhao Z, Chen L, Wang Z, Burmeister M, et al. Mental health of young physicians in china during the novel coronavirus disease 2019 outbreak. JAMA Network Open. (2020) 3:e2010705. doi: 10.1001/jamanetworkopen.2020.10705

35. Liang Y, Chen M, Zheng X, Liu J. Screening for Chinese medical staff mental health by SDS and SAS during the outbreak of COVID-19. J Psychosom Res. (2020) 133:110102. doi: 10.1016/j.jpsychores.2020.110102

36. Liu CY, Yang YZ, Zhang XM, Xu X, Dou QL, Zhang WW, et al. The prevalence and influencing factors in anxiety in medical workers fighting COVID-19 in China: a cross-sectional survey. Epidemiology Infect. (2020) 148:e98. doi: 10.1017/S0950268820001107

37. Lu W, Wang H, Lin Y, Li L. Psychological status of medical workforce during the COVID-19 pandemic: a cross-sectional study. Psychiatry Res. (2020) 288:112936. doi: $10.1016 /$ j.psychres.2020.112936

38. Morgantini LA, Naha U, Wang H, Francavilla S, Acar Ö, Flores JM, et al. Factors contributing to healthcare professional burnout during the COVID-19 pandemic: a rapid turnaround global survey. medRxiv. (2020). doi: 10.1101/2020.05.17.20101915

39. Ni MY, Yang L, Leung CM, Li N, Yao XI, Wang Y, et al. Mental health, risk factors, and social media use during the COVID-19 epidemic and cordon sanitaire among the community and health professionals in Wuhan, China: cross-sectional survey. JMIR Ment Health. (2020) 7:e19009. doi: 10.2196/19009

40. Podder I, Agarwal K, Datta S. Comparative analysis of perceived stress in dermatologists and other physicians during home-quarantine and COVID-19 pandemic with exploration of possible risk factors-A web-based cross-sectional study from Eastern India. Dermatol Ther. (2020). 33:1-7. doi: $10.1111 /$ dth. 13788

41. Qi J, Xu J, Li BZ, Huang JS, Yang Y, Zhang ZT, et al. The evaluation of sleep disturbances for Chinese frontline medical workers under the outbreak of COVID-19. Sleep Med. (2020). 72:1-4. doi: 10.1101/2020.03.06.200 31278

42. Liu Q, Luo D, Haase JE, Guo Q, Wang XQ, Liu S, et al. The experiences of health-care providers during the COVID-19 crisis in China: a qualitative study. Lancet Global Health. (2020) 8:e790-8. doi: 10.1016/S2214-109X(20)30204-7

43. Ramaci T, Barattucci M, Ledda C, Rapisarda V. Social stigma during COVID-19 and its impact on HCWs outcomes. Sustainability. (2020) 12:3834. doi: $10.3390 /$ su12093834

44. Rossi R, Socci V, Pacitti F, Di Lorenzo G, Di Marco A, Siracusano A, et al. Mental health outcomes among frontline and second-line health care workers during the coronavirus disease 2019 (COVID-19) Pandemic in Italy. JAMA Netw Open. (2020) 3:e2010185. doi: 10.1001/jamanetworkopen.2020. 10185

45. Salman M, Raza MH, Mustafa ZU, Khan TM, Asif N, Tahir H, et al. The psychological effects of COVID-19 on frontline healthcare workers and how they are coping: a web-based, cross-sectional study from Pakistan. medRxiv. (2020). doi: 10.1101/2020.06.03.20119867

46. Shariati B, Ardebili ME, Shalbafan M. Working in the emergency and inpatient COVID-19 special wards: a different experience for Iranian psychiatric trainees amid the outbreak. Asian J Psychiatry. (2020) 51:102157. doi: 10.1016/j.ajp.2020.102157 
47. Sheng X, Liu F, Zhou J, Liao R. Psychological status and sleep quality of nursing interns during the outbreak of COVID-19. Nan Fang Yi Ke Da Xue Xue Bao. (2020) 40:346-50. doi: 10.12122/j.issn.1673-4254.2020.03.09

48. Song X, Fu W, Liu X, Luo Z, Wang R, Zhou N, et al. Mental health status of medical staff in emergency departments during the coronavirus disease 2019 epidemic in China. Brain Behav Immun. (2020) 88:605. doi: 10.1016/j.bbi.2020.06.002

49. Sun N, Wei L, Shi S, Jiao D, Song R, Ma L, et al. A qualitative study on the psychological experience of caregivers of COVID-19 patients. Am J Infect Contr. (2020) 48:592-8. doi: 10.1016/j.ajic.2020.03.018

50. Temsah MH, Al-Sohime F, Alamro N, Al-Eyadhy A, Al-Hasan K, Jamal A, et al. The psychological impact of COVID-19 pandemic on health care workers in a MERS-CoV endemic country. J Infect Public Health. (2020) 13:877-82. doi: 10.1016/j.jiph.2020.05.021

51. Tian T, Meng F, Pan W, Zhang S, Cheung T, Ng CH, et al. Mental health burden of frontline health professionals treating imported patients with COVID-19 in China during the pandemic. Psychol Med. (2020) 12. doi: 10.1017/S0033291720002093

52. Wang S, Xie L, Xu Y, Yu S, Yao B, Xiang D. Sleep disturbances among medical workers during the outbreak of COVID-2019. Occup Med. (2020) 70:364-9. doi: 10.1093/occmed/kqaa074

53. Zhang WR, Wang K, Yin L, Zhao WF, Xue Q, Peng M, et al. Mental health and psychosocial problems of medical health workers during the COVID-19 epidemic in China. Psychother Psychosom. (2020) 89:24250. doi: $10.1159 / 000507639$

54. Wu W, Zhang Y, Wang P, Zhang L, Wang G, Lei G, et al. Psychological stress of medical staffs during outbreak of COVID-19 and adjustment strategy. J Med Virol. (2020) 92:1962-70. doi: 10.1002/jmv.25914

55. Wu K, Wei X. Analysis of psychological and sleep status and exercise rehabilitation of front-line clinical staff in the fight against COVID-19 in China. Med Sic Monit Basic Res. (2020) 26:e924085. doi: 10.12659/MSMBR.924085

56. Xing J, Sun N, Xu J, Geng S, Li Y. Study of the mental health status of medical personnel dealing with new coronavirus pneumonia. PloS ONE. (2020) 15:e0233145. doi: 10.1371/journal.pone.0233145

57. Xu J, Xu QH, Wang CM, Wang J. Psychological status of surgical staff during the COVID-19 outbreak. Psychiatry Res. (2020) 288:112955. doi: 10.1016/j.psychres.2020.112955

58. Yang S, Kwak SG, Ko EJ, Chang MC. The mental health burden of the COVID19 pandemic on physical therapists. Int J Environ Res Public Health. (2020) 17:3723. doi: 10.3390/ijerph17103723

59. Yin Q, Sun Z, Liu T, Ni X, Deng X, Jia Y, et al. Posttraumatic stress symptoms of health care workers during the corona virus disease 2019 (COVID-19). Clin Psychol Psychother. (2020) 27:384-95. doi: 10.1002/cpp.2477

60. Zhang SX, Liu J, Jahanshahi AA, Nawaser K, Yousefi A, Li J, et al. At the height of the storm: healthcare staff's health conditions and job satisfaction and their associated predictors during the epidemic peak of COVID-19. Brain Behav Immun. (2020) 87:144-6. doi: 10.1016/j.bbi.2020.05.010

61. Zhang C, Yang L, Liu S, Ma S, Wang Y, Cai Z, et al. Survey of insomnia and related social psychological factors among medical staff involved in the 2019 novel coronavirus disease outbreak. Front Psychiatry. (2020) 11:306. doi: 10.3389/fpsyt.2020.00306

62. Liu Z, Han B, Jiang R, Huang Y, Ma C, Wen J, et al. Mental health status of doctors and nurses during COVID-19 epidemic in China. MedRxiv. (2020). doi: 10.2139/ssrn.3551329

63. Zhou Y, Zhou Y, Song Y, Ren L, Ng CH, Xiang YT, et al. Tackling the mental health burden of frontline healthcare staff in the COVID-19 pandemic: China's experiences. Psychol Med. (2020) 1-5. doi: 10.1017/S0033291720001622
64. Zhu Z, Xu S, Wang H, Liu Z, Wu J, Li G, et al. COVID-19 in Wuhan: immediate psychological impact on 5062 health workers. MedRxiv. (2020). doi: 10.1101/2020.02.20.20025338

65. Spoorthy MS, Pratapa SK, Mahant S. Mental health problems faced by healthcare workers due to the COVID-19 pandemic-a review. Asian J Psychiatry. (2020) 51:102119. doi: 10.1016/j.ajp.2020. 102119

66. Rajkumar RP. COVID-19 and mental health: a review of the existing literature. Asian J Psychiatry. (2020) 52:102066. doi: 10.1016/j.ajp.2020. 102066

67. Bohlken J, Schömig F, Lemke MR, Pumberger M, Riedel-Heller SG. COVID19 pandemic: stress experience of healthcare workers-a short current review. Psychiatr Praxis. (2020) 47:190-7. doi: 10.1055/a-1159-5551

68. de Pablo GS, Serrano JV, Catalan A, Arango C, Moreno C, Ferre F, et al Impact of coronavirus syndromes on physical and mental health of health care workers: Systematic review and meta-analysis. J Affect Disord. (2020) 275:48-57. doi: 10.1016/j.jad.2020.06.022

69. da Silva FC, Neto ML. Psychiatric symptomatology associated with depression, anxiety, distress, and insomnia in health professionals working in patients affected by COVID-19: A systematic review with meta-analysis. Prog Neuro Psychopharmacol Biol Psychiatry. (2020) 104:110057. doi: 10.1016/j.pnpbp.2020.110057

70. Paiano M, Jaques AE, Nacamura PA, Salci MA, Radovanovic CA, Carreira L. Mental health of healthcare professionals in China during the new coronavirus pandemic: an integrative review. Rev Brasil de Enfermagem. (2020) 73:e20200338. doi: 10.1590/0034-7167-2020-0338

71. Thombs BD, Bonardi O, Rice DB, Boruff JT, Azar M, He C, et al Curating evidence on mental health during COVID-19: a living systematic review. J Psychosom Res. (2020). 133:1-3. doi: 10.1016/j.jpsychores.2020. 110113

72. Matsuo T, Kobayashi D, Taki F, Sakamoto F, Uehara Y, Mori N, et al Prevalence of health care worker burnout during the coronavirus disease 2019 (COVID-19) pandemic in Japan. JAMA Network Open. (2020) 3:e2017271. doi: 10.1001/jamanetworkopen.2020.17271

73. Manasi Kumar PK. (2020). Impact of Pandemic on Mental Health in Lowerand-Middle Income Countries (LMICs). Cambridge University Press

74. United States. United Nations Policy Brief: COVID-19 and the Need for Action on Mental Health. United Nations (2020).

75. World Health Organization. Mental health and psychosocial considerations during the COVID-19 outbreak, 18 March 2020. World Health Organization (2020).

76. National Academy of Medicine. Clinician Wellbeing Resources during COVID-19. National Academy of Medicine (2020). Available online at: https://nam.edu/initiatives/clinician-resilience-and-well-being/clinicianwell-being-resources-during-covid-19/ (accessed December 26, 2020).

Conflict of Interest: The authors declare that the research was conducted in the absence of any commercial or financial relationships that could be construed as a potential conflict of interest.

Copyright (c) 2021 Moitra, Rahman, Collins, Gohar, Weaver, Kinuthia, Rössler, Petersen, Unutzer, Saxena, Huang, Lai and Kumar. This is an open-access article distributed under the terms of the Creative Commons Attribution License (CC BY). The use, distribution or reproduction in other forums is permitted, provided the original author(s) and the copyright owner(s) are credited and that the original publication in this journal is cited, in accordance with accepted academic practice. No use, distribution or reproduction is permitted which does not comply with these terms. 